\title{
The relationship between clustering health-promoting components of lifestyle and bone status among middle-aged women in a general population
}

\author{
Satoshi Tsuboi · Takehito Hayakawa • \\ Hideyuki Kanda · Tetsuhito Fukushima
}

Received: 23 February 2009/ Accepted: 7 July 2009/Published online: 28 July 2009

(C) The Japanese Society for Hygiene 2009

\begin{abstract}
Objective The association between clustering healthpromoting components of lifestyle and bone status was examined among middle-aged women.

Methods A cross-sectional study was conducted in Tadami Town, Fukushima Prefecture, Japan, in 2007. A total of 305 middle-aged women (mean age 55.2 years) participated. The Health-Promoting Lifestyle Profile II was used to assess health-promoting components of lifestyle. Participants' bone status was examined using quantitative ultrasonic calcaneal measurement.

Results A total of 139 participants (45.6\%) were defined as having low bone stiffness. In the low bone stiffness group, the mean age was significantly higher, and prevalence of interpersonal relationships score over 3.0 was lower than that in the normal bone stiffness group. There were significant trends in the prevalence of low bone stiffness, each health-promoting component of lifestyle, and presence of hypertension and diabetes mellitus, based on the number of frequently selected health-promoting components of lifestyle. The number of frequently selected health-promoting components of lifestyle correlated negatively with the prevalence of low bone stiffness in both crude and adjusted results.

Conclusion This research is particularly important as we suggest health-promotion strategies for the prevention of osteoporosis. A synthetic approach, which includes health responsibility, spiritual growth, interpersonal relations, and
\end{abstract}

S. Tsuboi $(\bowtie) \cdot$ T. Hayakawa $\cdot$ H. Kanda - T. Fukushima Department of Hygiene and Preventive Medicine,

School of Medicine, Fukushima Medical University,

1 Hikarigaoka, Fukushima 960-1295, Japan

e-mail: tsuboi@fmu.ac.jp stress management, and physical activity and nutrition, may be effective and complement traditional strategies.

Keywords Osteoporosis $\cdot$ Middle-aged $\cdot$ Health promotion · Health behavior - Lifestyle modification

\section{Introduction}

Osteoporosis is defined as a skeletal disorder characterized by compromised bone strength predisposing to an increased risk of fracture [1]. According to the World Health Organization, osteoporosis affects more than 75 million individuals in Europe, Japan, and the USA, causing more than 2.3 million fractures annually in Europe and the USA alone [2]. Osteoporotic fractures cause loss of independence and reduce quality of life (QOL) with aging [3]. In 2005, it was estimated that $19.9 \%$ of Japanese individuals were over 65 years of age; this proportion is projected to increase to $26.0 \%$ in 2015 and $35.7 \%$ in 2050 [4]. This trend is observed worldwide, with increasing importance being attached to prevention of osteoporosis in order to improve well-being and longevity. Because osteoporosis is asymptomatic until a fracture occurs, primary prevention is one of the most important strategies.

Low bone mineral density (BMD) is one of the risk factors for osteoporotic fractures in middle-aged women [5], and accelerated bone loss is observed in this age group with decreasing estrogen secretion [6]. Thus, middle-aged women are one of the most important target groups for primary prevention. There are also many lifestyle-related risk factors for bone loss: sedentary behavior and low levels of physical activity [7], low dietary calcium and vitamin D intake [8], less than optimal body weight for health [9], use of tobacco products [10], and excess consumption of 
alcohol [11]. These risk factors and behaviors have been well studied. However, the relationships between bone status and a health-promoting lifestyle are not well understood.

A health-promoting lifestyle, which is defined as a "multidimensional pattern of self-initiated actions and perceptions that serve to maintain or enhance the level of wellness, self-actualization, and fulfillment of the individual" [12], is measured by the Health-Promoting Lifestyle Profile II (HPLP II) [13]. This instrument consists of six components (health responsibility, spiritual growth, physical activity, interpersonal relations, nutrition, and stress management), and describes lifestyle patterns. Previous studies have emphasized the importance of lifestyle patterns in establishing effective interventions [14, 15]. Moreover, other studies have shown that health behaviors, some of which are health-promoting components of lifestyle, tend to cluster in the same individuals [16, 17]. Furthermore, the impact of clustering health behaviors on risk of cardiovascular disease has been well documented [18]. However, the relationship between bone status and clustering health-promoting components of lifestyle is not well known. Exploring this relationship may therefore suggest additional lifestyle-based health-promotion strategies for prevention of osteoporosis.

In this study, the relationship between health-promoting components of lifestyle and bone status was examined in middle-aged women in the general population in order to explore additional strategies for the prevention of osteoporosis.

\section{Materials and methods}

Study design and subjects

A cross-sectional study was conducted in July 2007 in Tadami Town, Fukushima Prefecture, Japan. The total population of this town was 5,402, and the proportion of people aged over 65 years was about $40 \%$ in 2007. Annual health check-ups were held in Tadami Town in 2007, and 1,893 men and women participated. Of these, 351 were middle-aged women aged 40-64 years. When we informed them about this study, 46 declined to participate and 305 $(86.9 \%)$ consented to participate. All of the subjects could walk unaided and appeared healthy. This study was approved by the Institutional Review Board of Fukushima Medical University (no. 574).

General health status

The subjects provided self-reported information regarding their age, smoking status, alcohol consumption, and disease status (whether receiving regular outpatient treatment for hypertension, dyslipidemia, or diabetes mellitus). Public health nurses checked gaps or errors on questionnaire forms, and asked subjects to complete or correct such items. Public health nurses also measured participants' weight, height, and bone properties using quantitative ultrasonic (QUS) calcaneal measurements. Body mass index (BMI) was calculated as weight $(\mathrm{kg}) / \mathrm{height}(\mathrm{m})^{2}$.

\section{Health-Promoting Lifestyle Profile II (HPLP II)}

HPLP II is composed of 52-item questionnaire answered according to a four-point scale: 1 never, 2 sometimes, 3 often, and 4 routinely. The instrument consists of six subscales: health responsibility (e.g., discuss health concerns, seek information to take good care of myself), spiritual growth (e.g., feel life has a purpose, look forward to the future), physical activity (e.g., do vigorous exercise three times/week, do moderate physical activity), interpersonal relationships (e.g., get support, maintain meaningful interpersonal relationships), nutrition (e.g., eat breakfast, limit sugars), and stress management (e.g., get enough sleep, maintain balance between work and play). With regard to the validation of this instrument, the alpha reliability coefficient for these six health-promoting components of lifestyle ranged from 0.70 to 0.87 in a Japanese-language version of the HPLP II [13]. Wiley and Camacho defined lifestyle as "discretionary activities with significant impact on health status that are a regular part of one's daily pattern of living" [19], and HPLP II was constructed on the basis of this definition [12]. Moreover, previous studies have assessed lifestyle with regard to whether public health recommendations were met, and pointed out the importance of a comprehensive and cumulative measure of assessment [17]. On the basis of these previous studies, we defined health-promoting components of lifestyle that scored $\geq 3.0$ (often-routinely) as frequently selected. We created a cumulative term summing up the number of frequently selected health-promoting components of lifestyle in addition to assessment with continuous variables of HPLP II.

Quantitative ultrasonic (QUS) calcaneal measurement

The reproducibility and validity of the calcaneal QUS procedure have been established previously [20]. Although dual-energy X-ray absorptiometry (DXA) is the gold standard in the measurement of BMD, QUS is another promising technology thought to reflect bone stiffness, and a strong correlation has been found between calcaneal DXA measurements and calcaneal QUS measurements $(r=0.859)$ [21]. In this study, we performed calcaneal QUS (AOS 100; Aloka, Mitaka, Tokyo, Japan), and obtained the osteosonic index (OSI), which is calculated 
from the speed of sound (SOS) and the transmission index (TI). The OSI is the ultrasound velocity through the dominant heel, and the transmission index (TI) is a value that is proposed to be related to the frequency-dependent attenuation, or broad band ultrasound attenuation (BUA)[20]. The OSI is calculated using these two indices (OSI = $\mathrm{TI} \times \mathrm{SOS}^{2}$ ) and provides information on bone stiffness. The precision of the AOS 100 is expressed by the coefficient of variation (CV), and the CV of OSI was $2.2 \%$ [20]. The $T$ score of the OSI was calculated by comparing the current subjects' OSIs (OSI subjects) with the mean OSI value obtained from young healthy Japanese adults aged 20-44 years (OSI young-normal), using the equation: $T$ score $=($ OSI subjects - OSI young-normal $) / S D$ youngnormal, where SD young-normal is the standard deviation (SD) of the values for young adults.

Although QUS seems to be a good predictor of fractures without radiation exposure [22, 23], it is thought to be a screening method rather than a technique for diagnostic classification, and internationally accepted criteria for screening osteoporosis with QUS are not yet established [24-27]. According to the Japanese criteria for screening osteoporosis [28, 29], an OSI less than 2.428 (90\% of OSI young-normal; $T$ score $=-0.9$ ) is thought to signal the need to change one's lifestyle to prevent osteoporosis. Thus, in this study, we defined people with an OSI under 2.428 as having low bone stiffness and focused on them.

\section{Statistical analyses}

In the analysis of bone stiffness and characteristics, the non-paired Student's $t$ test was used to analyze differences in age and BMI, and the $\chi^{2}$ test was used to analyze differences in each of the frequently selected health-promoting components of lifestyle, and current smoking; current drinking; and presence of hypertension, dyslipidemia, and diabetes mellitus with respect to bone stiffness. In the analysis of cumulative health-promoting components of lifestyle, a trend test was used to analyze differences in age; BMI; the prevalence of low bone stiffness; each of the six frequently selected health-promoting components of lifestyle; current smoking; current drinking; and presence of hypertension, dyslipidemia, and diabetes mellitus with respect to the number of frequently selected health-promoting components of lifestyle. Multiple regression analysis was used in subjects with low bone stiffness to assess trends with respect to the number of health-promoting components of lifestyle (crude and adjusted for age, BMI, current smoking, current drinking, and presence of hypertension and diabetes mellitus). All statistical differences were tested at the 0.05 level of significance. The Statistical Package for the Social Sciences (version 15.0J; SPSS Japan, Tokyo, Japan) was used to perform all analyses.

\section{Results}

Figure 1 shows the distribution of $O S I$, and Table 1 shows that, on the basis of QUS, 139 subjects (45.6\% of 305 subjects) were defined as having low bone stiffness. The mean age of the low bone stiffness group was significantly higher than that of the normal bone stiffness group. Among the six frequently selected health-promoting components of lifestyle, only interpersonal relationships was significantly higher in the normal bone stiffness group (77.1\%) than in the low bone stiffness group (57.6\%). We also examined differences in health-promoting lifestyle (total score) as a continuous variable with Student's $t$ test, but we did not find a significant difference $(P=0.253)$.

The distribution of the number of frequently selected health-promoting components of lifestyle was as follows: $0, n=41(13.4 \%) ; 1, n=71(23.3 \%) ; 2, n=72(23.6 \%)$;
Fig. 1 Distribution of osteosonic index (OSI) among 305 middle-aged women in Tadami Town, Fukushima, Japan, 2007. Low bone stiffness (OSI < 2.428) was identified in 139 subjects $(45.6 \%)$

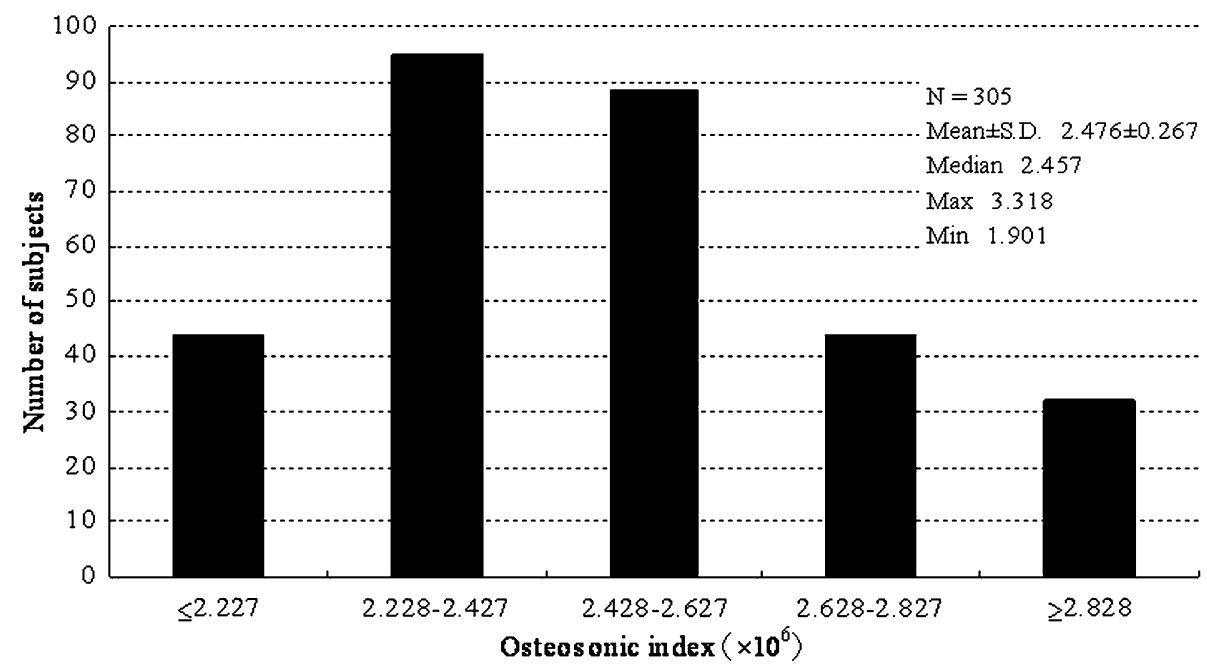

Osteos onic index $\left(\times 10^{6}\right)$ 
Table 1 Mean $( \pm \mathrm{SD})$ and prevalence of characteristics for subjects with normal bone stiffness (OSI $\geq 2.428)$ and low bone stiffness $($ OSI $<2.428)$ among 305 middle-aged women in Tadami Town, Fukushima, Japan, 2007

\begin{tabular}{|c|c|c|c|c|}
\hline & $\begin{array}{l}\text { Normal bone stiffness } \\
(n=166)\end{array}$ & $\begin{array}{l}\text { Low bone stiffness } \\
(n=139)\end{array}$ & $\begin{array}{l}\text { Total } \\
(n=305)\end{array}$ & $P$ value \\
\hline Osteosonic index $\left(10^{6}\right.$, mean $\left.\pm \mathrm{SD}\right)$ & $2.666 \pm 0.196$ & $2.252 \pm 0.133$ & $2.476 \pm 0.267$ & - \\
\hline Age (years, mean $\pm \mathrm{SD})$ & $52.7 \pm 6.6$ & $58.2 \pm 5.1$ & $55.2 \pm 6.6$ & $<0.001^{\mathrm{c}}$ \\
\hline Body mass index $\left(\mathrm{kg} / \mathrm{m}^{2}\right.$, mean $\left.\pm \mathrm{SD}\right)$ & $23.3 \pm 3.5$ & $22.7 \pm 3.3$ & $23.0 \pm 3.5$ & $0.172^{\mathrm{c}}$ \\
\hline \multicolumn{5}{|c|}{ Frequently selected, health-promoting components of lifestyle ${ }^{a}$} \\
\hline Health responsibility $(\%)$ & 16.3 & 18.0 & 17.0 & $0.760^{\mathrm{d}}$ \\
\hline Spiritual growth $(\%)$ & 31.9 & 25.9 & 29.2 & $0.258^{\mathrm{d}}$ \\
\hline Physical activity $(\%)$ & 4.8 & 5.0 & 4.9 & $1.000^{\mathrm{d}}$ \\
\hline Interpersonal relationships $(\%)$ & 77.1 & 57.6 & 68.2 & $<0.001^{\mathrm{d}}$ \\
\hline Nutrition $(\%)$ & 64.5 & 60.4 & 62.6 & $0.478^{\mathrm{d}}$ \\
\hline Stress management $(\%)$ & 43.4 & 38.1 & 41.0 & $0.413^{\mathrm{d}}$ \\
\hline \multicolumn{5}{|l|}{ Habits } \\
\hline Current smoker $(\%)$ & 6.6 & 9.4 & 7.9 & $0.401^{\mathrm{d}}$ \\
\hline Current drinker $(\%)$ & 34.3 & 30.9 & 32.8 & $0.543^{\mathrm{d}}$ \\
\hline \multicolumn{5}{|l|}{ Disease status ${ }^{\mathrm{b}}$} \\
\hline Hypertension $(\%)$ & 11.4 & 18.0 & 14.4 & $0.140^{\mathrm{d}}$ \\
\hline Dyslipidemia (\%) & 10.2 & 12.2 & 11.1 & $0.590^{\mathrm{d}}$ \\
\hline Diabetes mellitus (\%) & 3.6 & 2.9 & 3.3 & $0.760^{\mathrm{d}}$ \\
\hline
\end{tabular}

${ }^{a}$ Frequently selected, health-promoting components of lifestyle were defined by a score of 3.0 or over for each component

b Disease status: percentage receiving regular outpatient treatment for hypertension, dyslipidemia, and diabetes mellitus

c The non-paired Student's $t$ test was used to analyze age and body mass index

${ }^{\mathrm{d}}$ The $\chi^{2}$-test was used to analyze frequently selected health-promoting components of lifestyle, habits, and disease status

$3, n=53$ (17.4\%); 4, $n=40(13.1 \%) ; 5, n=22(7.2 \%)$; and $6, n=6(2.0 \%)$. To give similar numbers of subjects in each category, we combined those who selected 4-6 components in the following analyses. Table 2 shows the distribution of each frequently selected health-promoting component of lifestyle and other characteristics by the number of frequently selected health-promoting components of lifestyle. There were no significant trends in age, BMI, OSI, current smoking, current drinking, or presence of dyslipidemia. However, there were significant trends in the prevalence of low bone stiffness, each health-promoting component of lifestyle, and presence of hypertension and diabetes mellitus based on the number of frequently selected health-promoting components of lifestyle. On the basis of general age at menopause of Japanese women, we divided subjects into two subgroups (age $>50, \leq 50$ ), and each subgroup showed the same trends in the prevalence of low bone stiffness. Therefore, we used combined data in the following analyses. There was no significant association between bone stiffness and health-promoting lifestyle (total score) as a continuous variable on multiple regression analysis (partial regression coefficient $=0.025, P=0.542$ ). Moreover, there was no significant relationship between bone stiffness and each health-promoting component of lifestyle treated as a continuous variable.
Table 3 shows the results of multiple regression analysis for crude figures and after adjusting for age, BMI, current smoking, current drinking, hypertension, and diabetes mellitus. In the crude results, partial regression coefficients of the number of frequently selected health-promoting components of lifestyle was -0.046 , and this result was statistically significant $(P=0.031)$. In the adjusted results, partial regression coefficient of the number of frequently selected health-promoting components of lifestyle was -0.042 , and this result was also statistically significant $(P=0.030)$. The number of frequently selected healthpromoting components of lifestyle correlated negatively with the prevalence of low bone stiffness in both crude and adjusted results.

\section{Discussion}

This study suggests that clustering health-promoting components of lifestyle may be an important public health construct for maintaining bone stiffness. The results demonstrate that bone stiffness was reflected by HPLP II, and there was a statistically significant trend for the proportion of women with low bone stiffness to decrease as the number of frequently selected health-promoting components of 
Table 2 Mean $( \pm$ SD) and prevalence of characteristics stratified by number of frequently selected health-promoting components of lifestyle among 305 middle-aged women in Tadami Town, Fukushima, Japan, 2007

\begin{tabular}{|c|c|c|c|c|c|c|}
\hline & \multicolumn{6}{|c|}{ Number of frequently selected health-promoting components of lifestyle } \\
\hline & $0(n=41)$ & $1(n=71)$ & $2(n=72)$ & $3(n=51)$ & $\geq 4(n=68)$ & $P$ value $^{\mathrm{d}}$ \\
\hline Age (years, Mean \pm S.D.) & $55.4 \pm 6.1$ & $55.4 \pm 6.4$ & $23.3 \pm 3.6$ & $54.6 \pm 6.2$ & $55.7 \pm 7.2$ & 0.944 \\
\hline Body mass index $\left(\mathrm{kg} / \mathrm{m}^{2}\right.$, mean $\left.\pm \mathrm{SD}\right)$ & $22.5 \pm 2.8$ & $22.9 \pm 2.8$ & 23.6 & $23.2 \pm 3.7$ & $22.9 \pm 3.1$ & 0.555 \\
\hline Osteosonic index $\left(10^{6}\right.$, mean $\left.\pm \mathrm{SD}\right)$ & $2.484 \pm 0.317$ & $2.402 \pm 0.261$ & $2.503 \pm 0.254$ & $2.532 \pm 0.227$ & $2.477 \pm 0.272$ & 0.225 \\
\hline $\begin{array}{l}\text { Prevalence of subjects with low } \\
\text { bone stiffness }^{\mathrm{a}}(\%)\end{array}$ & 53.7 & 59.2 & 40.3 & 28.3 & 45.6 & 0.031 \\
\hline \multicolumn{7}{|l|}{$\begin{array}{l}\text { Frequently selected, health-promoting } \\
\text { components of lifestyle }\end{array}$} \\
\hline Health responsibility (\%) & 0 & 2.8 & 4.2 & 17.0 & 55.9 & $<0.001$ \\
\hline Spiritual growth (\%) & 0 & 1.4 & 12.5 & 35.8 & 88.2 & $<0.001$ \\
\hline Physical activity (\%) & 0 & 0 & 0 & 0 & 22.1 & $<0.001$ \\
\hline Interpersonal relationships (\%) & 0 & 36.6 & 87.5 & 96.2 & 100 & $<0.001$ \\
\hline Nutrition (\%) & 0 & 46.5 & 69.4 & 83.0 & 94.1 & $<0.001$ \\
\hline Stress management $(\%)$ & 0 & 12.7 & 26.4 & 67.9 & 89.7 & $<0.001$ \\
\hline \multicolumn{7}{|l|}{ Habits } \\
\hline Current smoker (\%) & 4.9 & 14.1 & 9.7 & 1.9 & 5.9 & 0.219 \\
\hline Current drinker $(\%)$ & 36.6 & 33.8 & 38.9 & 30.2 & 25.0 & 0.154 \\
\hline \multicolumn{7}{|l|}{ Disease status ${ }^{\mathrm{c}}$} \\
\hline Hypertension (\%) & 14.6 & 9.9 & 15.3 & 3.8 & 26.5 & 0.096 \\
\hline Dyslipidemia (\%) & 12.2 & 8.5 & 9.7 & 9.4 & 16.2 & 0.348 \\
\hline Diabetes mellitus (\%) & 0 & 0 & 4.2 & 1.9 & 8.8 & 0.005 \\
\hline
\end{tabular}

${ }^{a}$ Prevalence of subjects with low bone stiffness: percentage of subjects having low bone stiffness (OSI $<2.428$ )

${ }^{\mathrm{b}}$ Frequently selected, health-promoting components of lifestyle were defined by a score of 3.0 or over for each component

${ }^{c}$ Disease status: percentage receiving regular outpatient treatment for hypertension, dyslipidemia, and diabetes mellitus

d Trend test was used to analyze all these factors

Table 3 Determinants of low bone stiffness: Trend analysis among 305 middle-aged women in Tadami Town, Fukushima, Japan, 2007

\begin{tabular}{llllr}
\hline & Partial regression coefficients & $95 \%$ confidence interval & $\mathrm{SE}^{\mathrm{a}}$ & $t$ \\
\hline Number of frequently selected, health-promoting components of lifestyle & & & \\
Crude & -0.046 & -0.087 to -0.004 & 0.053 & -2.174 \\
Adjusted $^{\mathrm{b}}$ & -0.042 & -0.079 to -0.004 & 0.019 & -2.179 \\
\hline
\end{tabular}

a Standard error

${ }^{\mathrm{b}}$ Result of multiple regression analysis adjusted by age, BMI, current smoker, current drinker, disease status including hypertension and diabetes mellitus

lifestyle increased. Even after adjusting for age, BMI, current smoking, current drinking, and regular outpatient treatment for hypertension and diabetes mellitus, this trend was significant. Moreover, bone stiffness differed significantly with regard to interpersonal relations. Interpersonal relationships therefore seem to be an additional key factor for maintaining bone stiffness. This is the first study to show the relationship between bone stiffness and clustering health-promoting components of lifestyle.

Previous studies have examined the effect of lifestyle interventions to prevent osteoporosis and have considered these to be promising strategies $[30,31]$. In this study, we found that the number of frequently selected health-promoting components of lifestyle was negatively correlated with the prevalence of low bone stiffness. This finding may help individuals to include health-promoting components of lifestyle in addition to avoiding risk behaviors in order to prevent osteoporosis. However, we could not find a significant association with continuous total score of HPLP II. This may be in part because variation in high-scoring health-promoting components of lifestyle at the individual level was balanced by low scoring components of others on population analysis. We also could not find a significant association between the continuous variable of OSI and the 
number of health-promoting components of lifestyle frequently selected. This may be in part because the number of subjects was small and the analysis was inadequately powered.

According to previous studies, to be maximally effective, interventions to change behavior must create expectations of a positive outcome [32]. Although relief from pain or symptoms often acts as an anticipated positive outcome, osteoporosis is asymptomatic until a fracture occurs. Therefore, other positive outcomes are needed; we believe that well-being is such an outcome. A health-promoting lifestyle is thought to be a positive approach which leads individuals toward well-being [12]. Previous studies also suggest that well-being may have some preventive effects, in addition to freedom from psychological disturbances [33]. Other studies $[34,35]$ suggest that bone deterioration may be negatively correlated with well-being. The present findings suggest that lifestyle modification toward wellbeing may help to prevent bone deterioration. A synthetic approach, which includes health responsibility, spiritual growth, interpersonal relationships, and stress management, and physical activity and nutrition, may therefore be effective and complement the traditional strategies.

This study is also one of the first to demonstrate a significant association between interpersonal relationships and bone stiffness. Previous studies suggest interpersonal relationships may be one of the most important components of well-being [36-38]. The results of this study are in agreement with these previous findings. Moreover, interpersonal relationships are thought to be an important component in community-based health-promotion strategies $[39,40]$. Our findings suggest that interpersonal relationships may also play a key role in health-promotion strategies for the prevention of osteoporosis in addition to already known factors. However, because relatively little evidence is available on this matter, additional research is needed before any interpretations are made.

This study had several limitations. First, a causal relationship between the clustering health-promoting components of lifestyle and bone stiffness cannot be inferred, although the cross-sectional data support the conclusion that these are associated. Second, this study involved a comparatively small number of subjects. Third, we assessed subjects' bone status with calcaneal QUS alone. QUS is a relatively new technique, and internationally accepted criteria for screening osteoporosis with QUS are not yet established. Finally, although the subjects were from a healthy general population and we analyzed bone stiffness adjusted for age to minimize the effect of age on results, we did not take a precise history of menopause or medication.

In conclusion, clustering health-promoting components of lifestyle are associated with bone stiffness. This research is particularly important as we suggest health-promotion strategies for the prevention of osteoporosis in addition to traditional strategies. This study also provides suggestions for additional research. Studies focusing on the reliability, validity, predictive strengths, and applied effectiveness of summary measures of clustering healthy lifestyle factors represent important next steps in this area. Additionally, the consideration of other lifestyle factors in the summary measure (e.g., sleep) is also important. Finally, we need more certain evidence of how to effectively facilitate clustering health-promoting components of lifestyle.

Acknowledgments Financial support for this study was provided by the Department of Hygiene and Preventive Medicine, Fukushima Medical University. The authors are grateful to the staff of the Health and Welfare Center of Tadami Town. They would also like to thank the subjects whose participation made this investigation possible.

\section{References}

1. National Institute of Health. Osteoporosis prevention, diagnosis, and therapy. NIH Consens Statement. 2000;17:1-45.

2. World Health Organization. Prevention and management of osteoporosis. World Health Organ Tech Rep Ser. 2003;921: 1-164 (back cover).

3. Chrischilles EA, Butler CD, Davis CS, Wallace RB. A model of lifetime osteoporosis impact. Arch Intern Med. 1991;151:202632.

4. Shigesato T, Akira I, Hisakazu K, Miho I, Ryuichi K, Ryuichi K, Masako I, Fusami M, Akiko T, Rie M. Population projections for Japan 2001-2050, with long-range population projections: 20512100. J Popul Social Security (Popul). 2003;1:1-43.

5. Kröger H, Huopio J, Honkanen R, Tuppurainen M, Puntila E, Alhava E, et al. Prediction of fracture risk using axial bone mineral density in a perimenopausal population; a prospective study. J Bone Miner Res. 1995;10:302-6.

6. Chapurlat RD, Garnero P, Sornay-Rendu E, Arlot ME, Claustrat $\mathrm{B}$, Delmas PD. Longitudinal study of bone loss in pre- and perimenopausal women: evidence for bone loss in perimenopausal women. Osteoporos Int. 2000;11:493-8.

7. Wolff I, van Croonenborg JJ, Kemper HC, Kostense PJ, Twisk JW. The effect of exercise training programs on bone mass: a meta-analysis of published controlled trials in pre- and postmenopausal women. Osteoporos Int. 1999;9:1-12.

8. Looker AC, Harris TB, Madans JH, Sempos CT. Dietary calcium and hip fracture risk: the NHANES I Epidemiologic Follow-Up Study. Osteoporos Int. 1993;3:177-84.

9. Pocock N, Eisman J, Bwinn T, Sambrook P, Kelly P, Freund J, et al. Muscle strength, physical fitness, and weight but not age predict femoral neck bone mass. J Bone Miner Res. 1989;4:441-8.

10. Kanis JA, Johnell O, Oden A, Johansson H, De Laet C, Eisman JA, et al. Smoking and fracture risk: a meta-analysis. Osteoporos Int. 2005; 16:155-62.

11. Kanis JA, Johansson H, Johnell CO, Oden A, De Laet C, Eisman JA. Alcohol intake as a risk factor for fracture. Osteoporos Int. 2005; $16: 737-42$.

12. Walker SN, Sechrist KR, Pender NJ. The Health-Promoting Lifestyle Profile: development and psychometric characteristics. Nurs Res. 1987;36:76-81.

13. Wei C-N, Yonemitsu H, Harada K, Miyakita T, Omori S, Miyabayashi T. A Japanese-language version of the HealthPromoting Lifestyle Profile. Jpn J Hyg. 2000;54:597-606. 
14. Reedy J, Haines PS, Campbell MK. The influence of health behavior clusters on dietary change. Prev Med. 2005;41:268-75.

15. O'Halloran P, Lazovich D, Patterson RE, Harnack L, French S, Curry SJ, et al. Effect of health lifestyle pattern on dietary change. Am J Health Promot. 2001;16:27-33.

16. Berrigan D, Dodd K, Troiano RP, Krebs-Smith SM, Barbash RB. Patterns of health behavior in US adults. Prev Med. 2003;36:61523.

17. Pronk NP, Anderson LH, Crain AL, Martinson BC, O'Connor PJ, Sherwood NE, et al. Meeting recommendations for multiple healthy lifestyle factors. prevalence, clustering, and predictors among adolescent, adult, and senior health plan members. Am J Prev Med. 2004;27:25-33.

18. Myint PK, Luben RN, Wareham NJ, Bingham SA, Khaw KT. Combined effect of health behaviors and risk of first ever stroke in 20, 040 men and women over 11 years' follow-up in Norfolk cohort of European prospective investigation of cancer (EPIC Norfolk): prospective population study. BMJ. 2009; 338:b349.

19. Wiley JA, Camacho TC. Lifestyle and future health: evidence from the Alameda county study. Prev Med. 1980;9:1-21.

20. Tsuda-Futami E, Hans D, Njeh CF, Fuerst T, Fan B, Li J, et al. An evaluation of a new gel-coupled ultrasound device for the quantitative assessment of bone. Br J Radiol. 1999;72:691-700.

21. Greenspan SL, Bouxsein ML, Melton ME, Kolodny AH, Clair $\mathrm{JH}$, Delucca PT, et al. Precision and discriminatory ability of calcaneal bone assessment technologies. J Bone Miner Res. 1997; 12:1303-13.

22. Fujiwara S, Sone T, Yamazaki K, Yoshimura N, Nakatsuka K, Masunari N, et al. Heel bone ultrasound predicts non-spine fracture in Japanese men and women. Osteoporos Int. 2005; 16:2107-12.

23. Hans D, Dargent-Molina P, Schott AM, Sebert JL, Cormier C, Kotzki PO, et al. Ultrasonographic heel measurements to predict hip fracture in elderly women: the EPIDOS prospective study. The Lancet. 1996;348:511-4.

24. Díez-Pérez A, Marín F, Vila J, Abizanda M, Cervera A, Carbonell $\mathrm{C}$, et al. Evaluation of calcaneal quantitative ultrasound in a primary care setting as a screening tool for osteoporosis in postmenopausal women. J Clin Densitom. 2003;6:237-45.

25. Hamidi Z, Sedaghat M, Hejri SM, Larijani B. Defining cut-off values for the diagnosis of osteoporosis in postmenopausal women by quantitative ultrasonography of the phalanx. Gynecol Endocrinol. 2008;24:546-8.

26. Minnock E, Cook R, Collins D, Tucker J, Zioupos P. Using risk factors and quantitative ultrasound to identify postmenopausal caucasian women at risk of osteoporosis. J Clin Densitom. 2008; 11:485-93.

27. Della Martina M, Fabiani G, Biasioli A, Piccoli V, Vascotto L, Driul L, et al. Identification of patients with a high risk of osteoporosis. Analysis of risk factors, ultrasonography and DEXA, in a female population in the North East of Italy. Minerva Ginecol. 2008;60:97-104.

28. The osteoporosis foundation. Manual of the prevention of osteoporosis by the law of health for the elderly. Tokyo: Japan medical journal; 2000. p. 61-85 (in Japanese).

29. Sakata S. Establishment of cut-off point of calcaneal quantitative ultrasound by population based data. J Bone Miner Metab. 1998;15: 171-6 (in Japanese).

30. Lock CA, Lecouturier J, Mason JM, Dickinson HO. Lifestyle interventions to prevent osteoporotic fractures: a systematic review. Osteoporos Int. 2006;17:20-8.

31. Pearson JA, Burkhart E, Pifalo WB, Palaggo-Toy T, Krohn K. A lifestyle modification intervention for the treatment of osteoporosis. Am J Health Promot. 2005;20:28-33.

32. McAlister AL. Population behavior change: a theory-based approach. J Public Health Policy. 1991;12:345-61.

33. Huppert FA, Whittington JE. Evidence for the independence of positive and negative well-being: implications for quality of life assessment. Br J Health Psychol. 2003;8(Pt 1):107-22.

34. Tai H, Miyaura C, Pilbeam CC, Tamura T, Ohsugi Y, Koishihara $\mathrm{Y}$, et al. Transcriptional induction of cyclooxygenase-2 in osteoblasts is involved in interleukin-6-induced osteoclast formation. Endocrinology. 1997;138:2372-9.

35. Friedman EM, Hayney M, Love GD, Singer BH, Ryff CD. Plasma interleukin-6 and soluble IL-6 receptors are associated with psychological well-being in aging women. Health Psychol. 2007;26:305-13.

36. Ohaeri JU, Olusina AK, Al-Abassi A-HM. Factor analytical study of the short version of the world health organization quality of life instrument. Psychopathology. 2004;37:242-8.

37. Emerson E, Hatton C. Self-reported well-being of women and men with intellectual disabilities in England. Am J Ment Retard. 2008;113:143-55.

38. Adams VHIII, Jackson JS. The contribution of hope to the quality of life among African Americans: 1980-1992. Int J Aging Hum Dev. 2000;50:279-95.

39. Galavotti C, Pappas-DeLuca KA, Lansky A. Modeling and reinforcement to combat HIV: The MARCH approach to behavior change. Am J Public Health. 2001;91:1602-7.

40. Kelly MP, Charlton BG, Hanlon P. The four levels of health promotion: an integrated approach. Public Health. 1993;107:319-26. 